Article

\title{
Numerical Investigation of Effect of Parameters on Hovering Efficiency of an Annular Lift Fan Aircraft
}

\author{
Yun Jiang * and Bo Zhang \\ UAV Research Institute, Northwestern Polytechnical University, 127 West Youyi Road, Xi'an 710072, China; \\ zhangbo_asn@163.com \\ * Correspondence: yunjiang273@gmail.com; Tel.: +86-29-8845-1027; Fax: +86-29-8845-1032 \\ Academic Editor: Mohammad Sadraey \\ Received: 14 August 2016; Accepted: 10 October 2016; Published: 19 October 2016
}

\begin{abstract}
The effects of various parameters on the hovering performance of an annular lift fan aircraft are investigated by using numerical scheme. The pitch angle, thickness, aspect ratio (chord length), number of blades, and radius of duct inlet lip are explored to optimize the figure of merit. The annular lift fan is also compared with a conventional circular lift fan of the same features with the same disc loading and similar geometry. The simulation results show that the pitch angle of $27^{\circ}$, the thickness of $4 \%$ chord length, the aspect ratio of 3.5 4.0, 32 blades, and the radius of inlet lip of $4.7 \%$ generate the maximum figure of merit of 0.733 . The optimized configuration can be used for further studies of the annular lift fan aircraft.
\end{abstract}

Keywords: annular duct; ducted fan; lift fan; hovering efficiency; optimization; aircraft

\section{Introduction}

Humans have been dreaming of building an airplane that can do "substantially everything that a bird can do in the air", as revered New York University aeronautical engineer Alexander Klemin described, that can take off, land and hover anywhere like a helicopter and also fly as fast as a fixed-wing plane. Many efforts has been made so far, but designing a machine that combines the agility of a helicopter with the speed and range of a fixed-wing aircraft have proven difficult, as shown by the example of the V-22 Osprey, whose history has been plagued by delays, technical problems, and orders of magnitude leaps in cost overruns. The Osprey and the Sikorsky X2 compound helicopter can fly faster than conventional helicopters, but both made significant aerodynamic compromise to hovering efficiency or range. Fixed-wing vertical takeoff and landing (VTOL) airplanes, such as the AV-8 Harrier, the F-35B Lightning II, and the Russia Yak-38 Forger, can hover for only a short time, at the cost of range, efficiency and useful load.

There are four types of successful and practical VTOL aircraft so far, which include helicopters, vectored jet aircraft, tiltrotors and ducted lift fan aircraft. These aircraft provide solutions to this problem, but also have some disadvantages. The lift fan concept was proposed for S/VTOL in the 1960s. It was first implemented in the jet powered experimental aircraft Ryan GE XV-5 with a fan-in-wing configuration [1]. Many experimental investigations have been conducted [2-4]. The core engines of the Ryan XV-5 provided a total thrust of 5300 pounds in forward flight mode, but could generate a total lift thrust of 16,000 pounds via the lift fans in hover mode [5]. Using the lift fans provided a 200\% increase in the total thrust when compared to the jet engine thrust alone, a clearly advantageous feature for vertical takeoff and landing aircraft. Besides the fan-in-wing, the fan-in-fuselage concept has also been successfully applied in the Lockheed Martin F-35B joint strike fighter [6]. Compared to conventional VTOL aircrafts, lift fan aircraft fly faster and require minimum ground preparation, without high discharge velocity and high surface temperatures to cause ground erosion and reingestion of hot gases which causes the lift engines to stall and lose lift [7-9]. Without exposed rotor, lift fans are 
also safer than helicopters and tiltrotors. The drawback of lift fans is that they add dead weight when not used in cruise flight.

No matter the fan-in-wing or the fan-in-fuselage configurations, the sizes of the lift fans are limited due to the constraints of the fuselage and wing sizes. Because of the small size, all the lift fans thus far are high disc loading in order to provide sufficient lift. According to the momentum theory of ducted fans $[9,10]$, high disc loading requires high power, thus leading to lower lift efficiency (power loading). To increase the lift efficiency, the fan area has to be increased to achieve low disc loading.

We proposed an annular lift fan concept with a central fuselage in the previous study to solve this problem [10] (Figure 1). The annular duct around the fuselage can greatly increase the lift fan area to achieve low disc loading and can also be easily shut off by shutters and louvers during cruise flight to provide aerodynamic lift and reduce drag. Because only half of the lift is generated by the fan (the other half is by the duct), the fan blades do not need to be very strong, thus can be made thin, narrow, hollow and of non-metal materials to reduce the dead weight. When the annular duct is closed, the occupied volume becomes part of ring wing in cruise flight. According to the computational fluid dynamics (CFD) simulation results [10], the annular lift fan aircraft with the same size of the Apache rotor can have higher lift efficiency in a hover and may fly much faster than helicopters in a cruise based on the aerodynamic drag predictions.

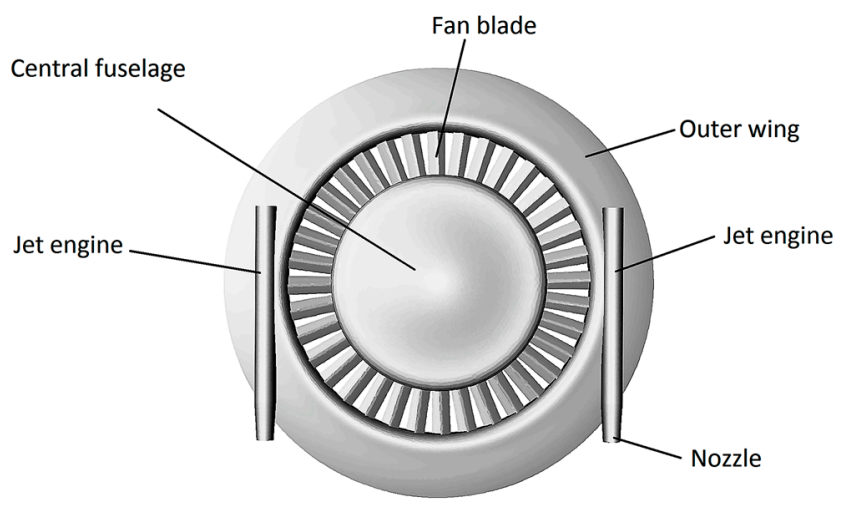

Figure 1. Annular lift fan aircraft.

The configuration of the annular lift fan system was explored in the previous study but not optimized [10]. In this study, we focused on the optimization of parameters of the annular lift fan system for hovering efficiency.

Although there are theories in ducted fan design $[7,9,11]$, the calculation methods are far from satisfying the requirements of the industry. As a result of advances in CFD, many aerodynamic researches have moved in the branch of CFD, which is more affordable, practical, systematic and reliable [12]. There are studies to numerically and experimentally investigate the aerodynamic characteristics of ducted fans in recent years $[1,13,14]$. Thouault et al. studied the transition characteristics of a fan-in-wing configuration in wind tunnel and compared the CFD results with the experimental data [1]. Akturk and Camci investigated the effects of tip clearance flow on aerodynamic performances of a ducted fan used in VTOL unmanned aerial vehicles and validated the numerical simulations with experimental data [13]. These researches not only demonstrate detailed flow field analysis but also provide valuable experimental data for others to validate the computational simulations of ducted fan.

In the present investigation, a computational method was used to explore the effect of blade geometry, number of blades, and duct inlet lip shapes, etc., on the hovering efficiency of the annular lift fan system and to optimize the parameters for the best hovering performances. 


\section{Geometry and Computational Mesh}

\subsection{Geometry Definition}

The original annular lift fan aircraft is shown in Figure 1. The fans in wing are mounted in the annular duct located between the central fuselage and the outer wing. The fans included an upper fan and a counter rotating lower fan to eliminate torque and swirl loss, but the two-stage fans were found to generate oscillations of lift and drag during transition due to the strong interactions between the fans [15], thus single-stage fans were used here for optimization. The single-stage vehicle also has thinner duct thus less aerodynamic drag in cruise flight. As shown in Figure 2a, the two single-stage fans including an inner fan and an outer fan [15] were horizontally and coaxially positioned to counter rotate at the same speed. The blade lengths of the two fans were selected for the fans to eliminate torque in hover mode. The length of inner fan blades is $1.35 \mathrm{~m}(r=6.35-5 \mathrm{~m})$; the length of outer fan blades is $0.65 \mathrm{~m}(r=7.1-6.45 \mathrm{~m})$. Two jet engines incorporated in the outer wing (Figure 1, not shown in Figure 2a) tip-drive the outer fan, which is coupled with the inner fan by the gears in the ring baffle.

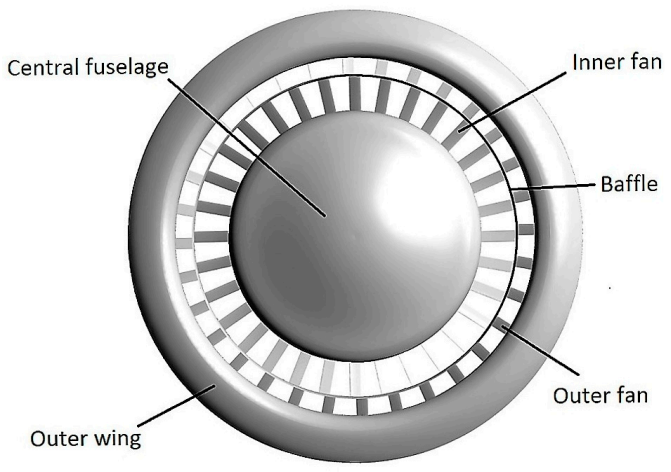

(a)

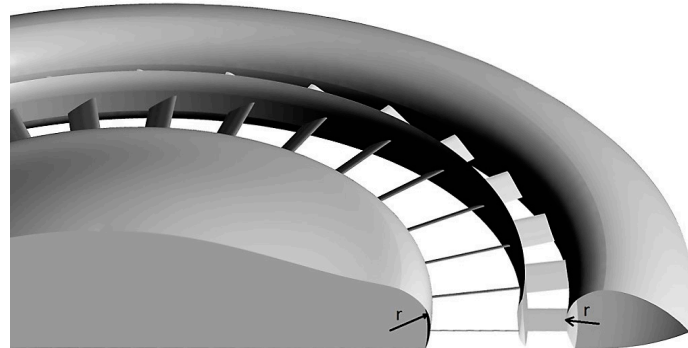

(b)

Figure 2. (a) single-stage annular lift fan aircraft; (b) the aircraft clipped in the central plane to show the radius of curvature of inlet lip $\left(R_{\text {lip }}\right)$. The jet engines were not considered in the simulations.

The same model as for the transition study [15] was used. The weight of aircraft is set as 10,433 kg, equal to the maximum takeoff weight of the Apache helicopter, with fan disc loading of $138.5 \mathrm{~kg} / \mathrm{m}^{2}$.

A generic simple airfoil with a flat surface and a cambered surface with the maximum thickness at about $20 \%$ of chord length from the leading edge was used in the optimization (Figure 3a, also see the pressure contour in the cross section plane of the inner fan in Section 5). The clearance gap between the fan tip and the duct is zero because the fan will be tip driven by the turbofan engines incorporated in the outer wing. With the tips fixed, the annular lift fan will also be quiet.

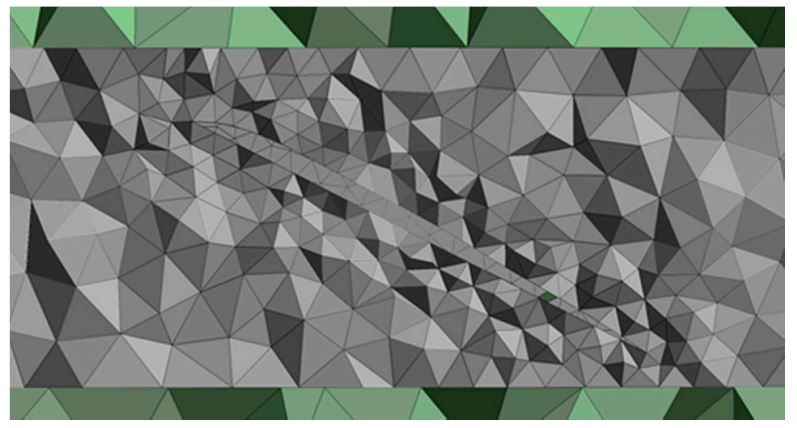

(a)

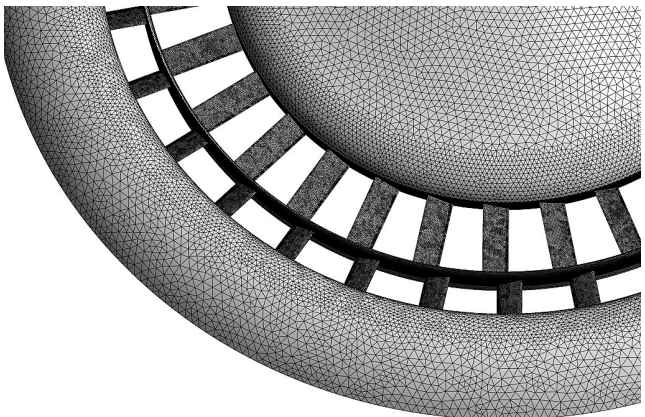

(b)

Figure 3. (a) Cross section mesh in the duct to show the geometry of blades. Different colors mean different blocks; (b) Surface mesh of the aircraft. 
The baseline model has a blade pitch angle of $27^{\circ}$, thickness of $4 \%$ chord length, aspect ratio of 2.27, and 32 blades. The annular duct has curved inlet lips and exit diffusers on both sides of the duct (Figure 2b). The geometry of the inlet lip shapes can be described by the radius of curvature of duct lip $\left(R_{\text {lip }}\right)$, which depicts the roundness of the duct lip. The $R_{\text {lip }}$ for the baseline is $2.5 \%$ of the duct diameter with the angle of inlet lip circle from $90^{\circ}$ to $135^{\circ}$.

\subsection{Computational Mesh}

The unstructured mesh technique was used in the study. CFD methods based on unstructured grids have an advantage of easily handling complex geometries and can improve the solution accuracy by refining cells locally as required [16]. The unstructured meshes in this study were created using ANSYS Meshing 17.0 (ANSYS, Inc., Canonsburg, PA, USA).

The tetrahedral volume meshes were created in a $15 R \times 15 R$ column flow field. $R$ is the radius of the aircraft. The upper boundary is located at $3 R$ above the aircraft and the lower boundary is $12 R$ under the aircraft to reduce the disturbances reflected from the outflow boundary. A dimension sensitivity study was carried out to make sure that the dimension was big enough so that the simulation results would not change with the computational fluid domain (data not shown).

Mesh sensitivity studies were carried out with three cases considered (Table 1). The result showed that the difference between medium and fine grid was small, so the simulations were performed with medium grid with 4.0 4.5 M cells. One of the surface meshes of the aircraft is shown in Figure 3a. The flow field was divided into two volumes in which the small block was dedicated to the fan.

Table 1. Grid sensitivity analysis in the figure of merit prediction study.

\begin{tabular}{cccc}
\hline Parameters & Coarse Grid & Medium Grid & Fine Grid \\
\hline Element number & $2.1 \mathrm{M}$ & $4.3 \mathrm{M}$ & $7.8 \mathrm{M}$ \\
Figure of merit & 0.663 & 0.675 & 0.679 \\
\hline
\end{tabular}

\section{Boundary Condition and Simulation Setup}

CFD simulations were performed using ANSYS Fluent 17.0, which has been extensively used in various studies [17-21]. The 3D Reynolds-averaged Navier-Stokes (RANS) equations for the mean flow quantities were solved.

A pressure-based solver type with absolute velocity formulation, the Green-Gauss node based gradient option and steady approach were used in the analyses. The shear stress transport (SST) $k-\omega$ turbulence model developed by Menter $[22,23]$ was selected. The semi implicit method for pressure linked equations (SIMPLE) scheme was used to resolve the pressure-velocity coupling with the second order discretization for the pressure equation, the third order monotonic upstream-centered scheme for conservation laws (MUSCL) for the momentum, turbulent kinetic energy and turbulent dissipation rate [12]. Multiple reference frames was used for the fan fluid zone and the stationary zone. Pressure-inlet and pressure-outlet boundary conditions were applied over the top and bottom surfaces of the computational domain.

\section{Numerical Model Validation}

The numerical model validation was performed on a conventional circular lift fan used in VTOL unmanned aerial vehicles (UAVs) [13]. As shown in Figure 4, the 8-bladed ducted fan is composed of a shroud, axial flow fan, curved inlet lip, and exit diffuser. The $559 \mathrm{~mm}$ diameter ducted fan was designed to provide a realistic disk loading typical of VTOL UAVs. The tip clearance is $1.71 \%$ of the rotor tip radius. The simulation results showed very good agreement with the experimental data in the figure of merit and thrust (Figure 5). The experimental data come from Akturk [13]. 


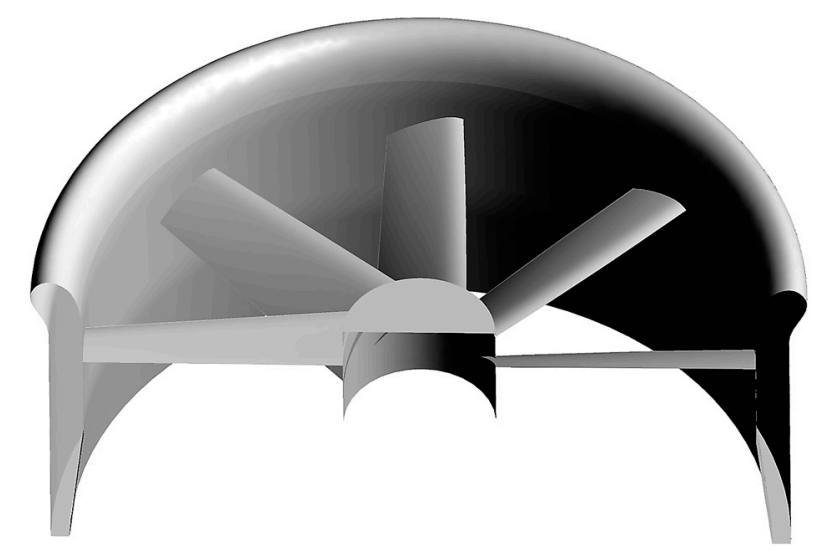

Figure 4. 8-bladed ducted fan clipped in the central plane.

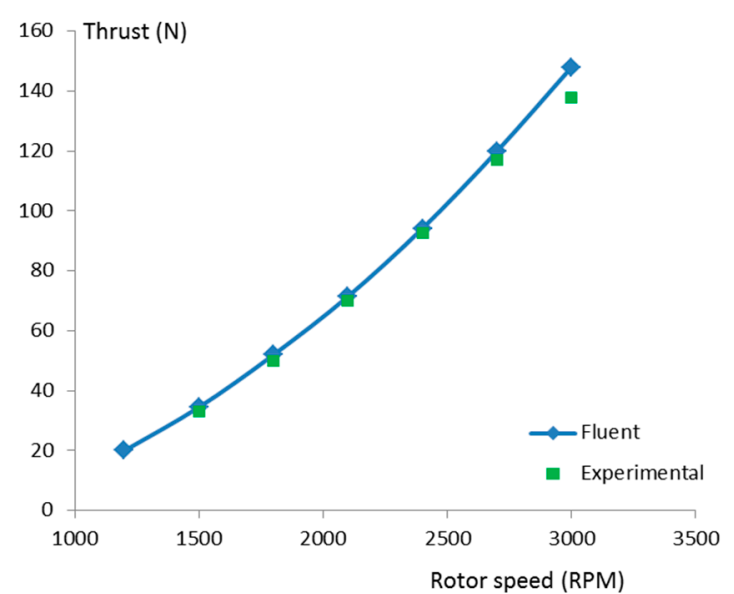

(a)

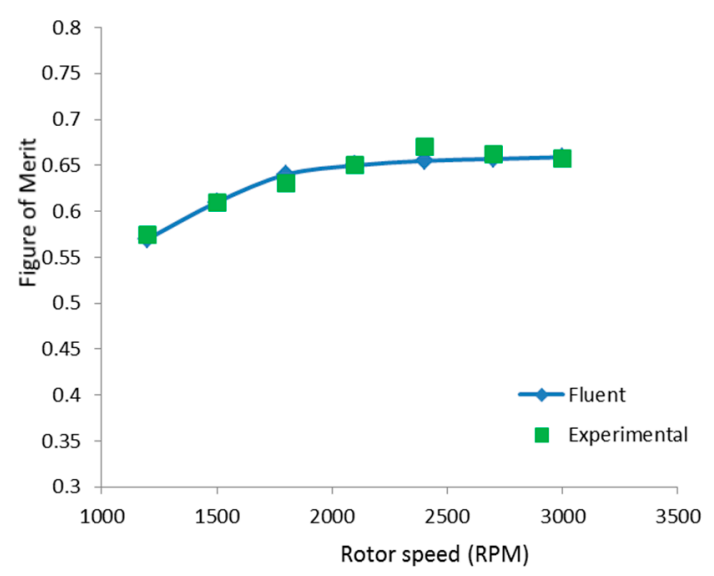

(b)

Figure 5. (a) Thrust versus rotor speed; (b) Figure of merit (FM) versus rotor speed.

\section{Results}

This section presents the numerical results obtained through simulations for various blade and inlet lip configurations. The figure of merit was calculated from ideal power and the actual power. The ideal power was calculated based on momentum theory [9]:

$$
P_{\text {ideal }}=\frac{T^{3 / 2}}{\sqrt{4 \sigma \rho A}}
$$

where $T$ is the total thrust; $A$ is the fan area; $\sigma$ is the duct diffusion ratio; $\rho$ is the density of air, $\rho=1.225 \mathrm{~kg} / \mathrm{m}^{3}$.

The duct diffusion ratio $\sigma$ was calculated from the fan thrust and the total thrust:

$$
\sigma=\frac{T}{2 T_{\mathrm{fan}}}
$$

The actual power was calculated according to the moment of the fan and the rotational speed:

$$
P_{\text {actual }}=\omega r F=2 \pi \frac{n}{60} r F
$$

where $r F$ together is the moment, which can be obtained directly from simulation result; $\omega(\mathrm{rad} / \mathrm{s})$ and $n(\mathrm{rpm})$ are the rotational speed. 
The figure of merit was calculated:

$$
F M=\frac{P_{\text {ideal }}}{P_{\text {actual }}}
$$

The pressure contour on the top surfaces of the vehicle and pressure distribution in the central plane are shown in Figure 6. Low pressure can be seen on the fans and duct inlet lips. With the specific blade lengths, the torque was eliminated when the two fans rotated at the same contrary speed. The thrusts of the inner fan and outer fan were close, about 25 and $23 \mathrm{kN}$. The total thrusts were maintained at $10,433 \mathrm{~kg}(102,243 \mathrm{~N})$ with disc loading of $138.5 \mathrm{~kg} / \mathrm{m}^{2}$ in all the simulations. The thrust was maintained by changing the rotational speed of fans. The $\sigma$ varied from 0.9 to 1.10 with the ideal powers around $1600-1800 \mathrm{kw}$. The actual powers ranged from 2300 to $2750 \mathrm{kw}$ with the rotational speeds changed from 120 to $190 \mathrm{rpm}$.
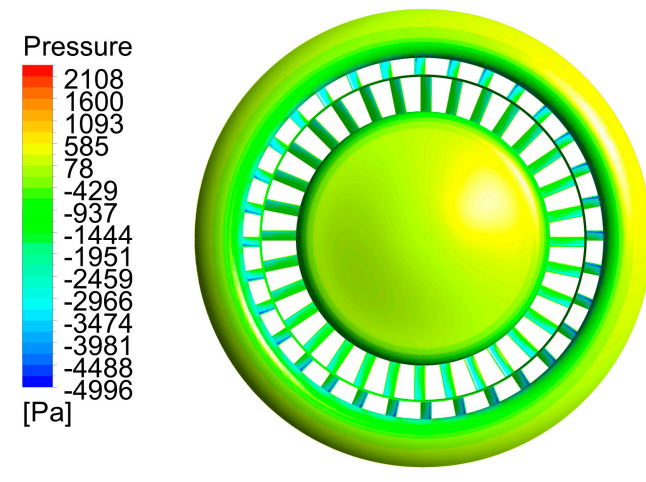

(a)

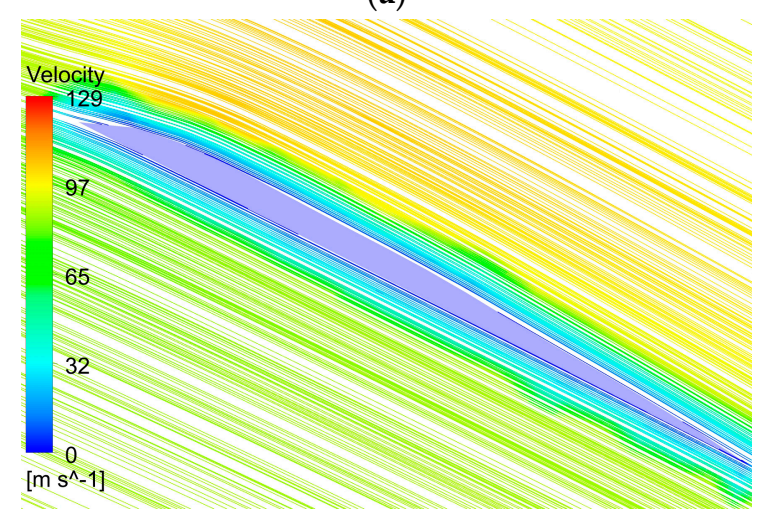

(c)

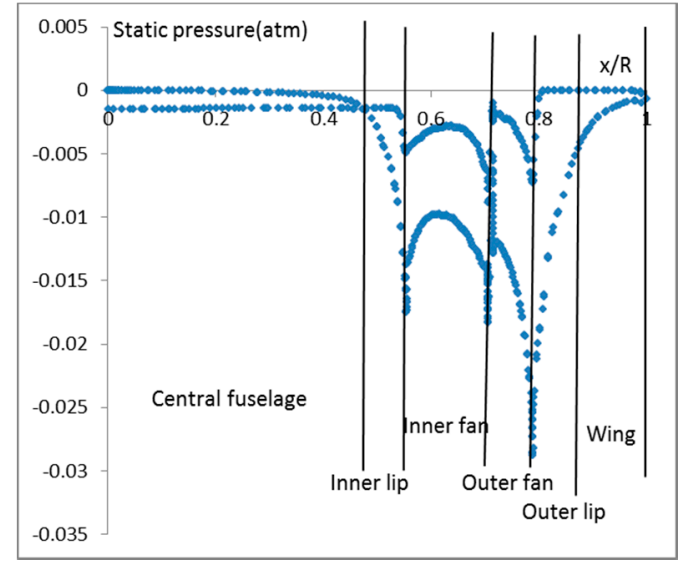

(b)

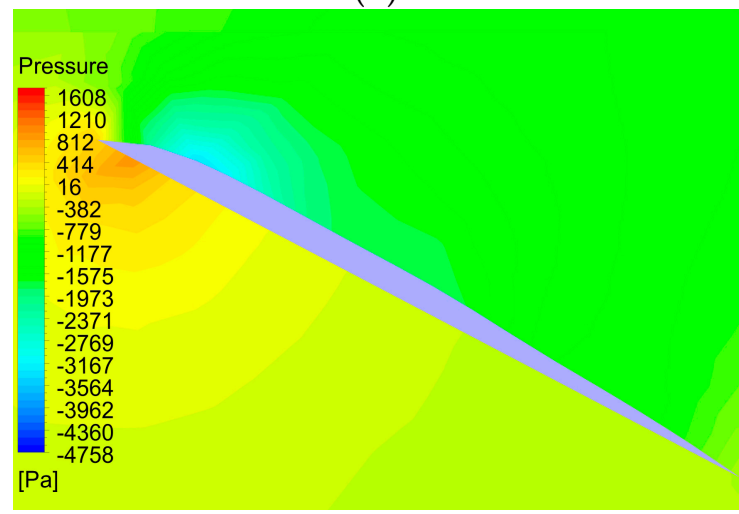

(d)

Figure 6. (a) Pressure contour on the top surfaces of annular ducted fans vehicle; (b) Static pressure distribution in the central plane of the vehicle; (c) Streamlines in the cross section plane of the inner fan; (d) Pressure contour in the cross section plane of the inner fan.

The simulations started from the baseline model with blade pitch angle of $27^{\circ}$, thickness of $4 \%$ chord length, aspect ratio of 2.27 , and 32 blades. The effect of blade pitch angle on the figure of merit is shown in Figure 7a. It is clear that the pitch angle of $27^{\circ}$ produced the maximum FM with the fan rotational speed of $137 \mathrm{rpm}$. This angle is higher than that of a helicopter rotor because of the higher velocity of inflow induced by ducted fan. 


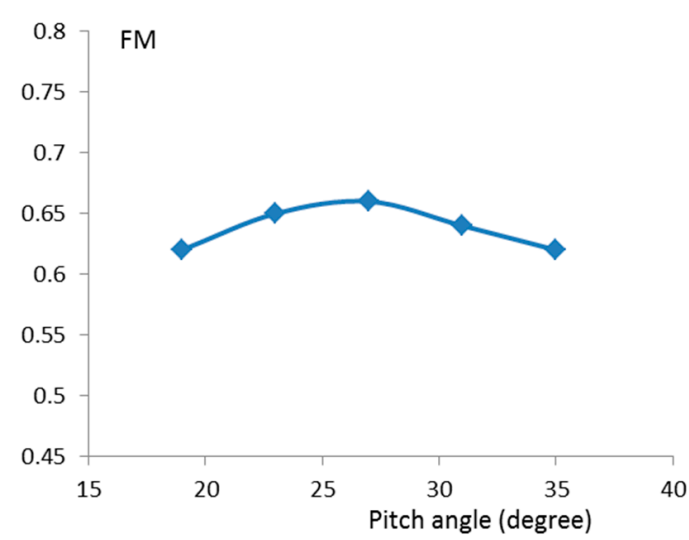

(a)

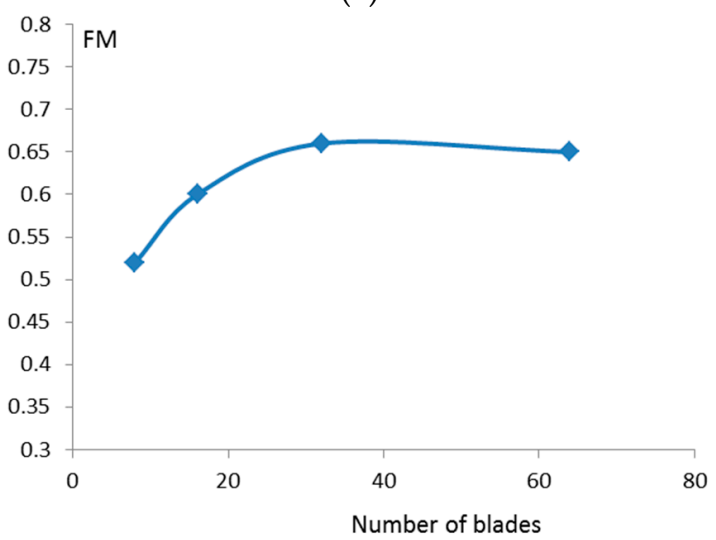

(c)

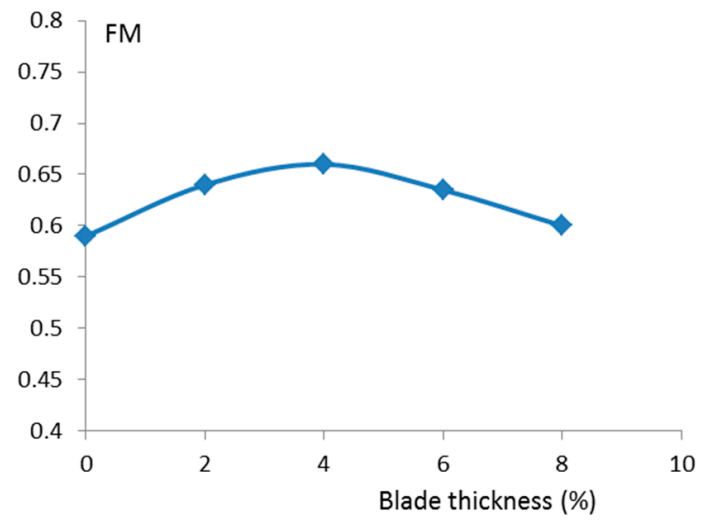

(b)

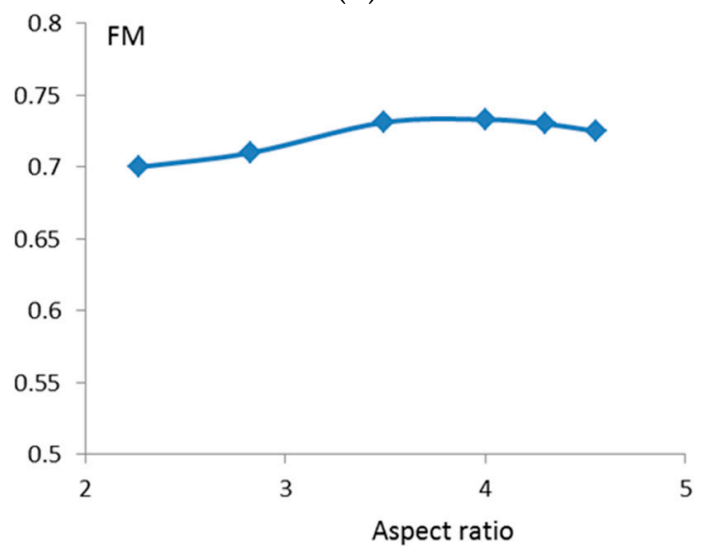

(d)

Figure 7. (a) FM versus pitch angle of blades; (b) FM versus blade thickness; (c) FM versus the number of blades; (d) FM versus aspect ratio.

With the pitch angle of $27^{\circ}$, the role of blade thickness in the figure of merit is shown in Figure $7 \mathrm{~b}$. The thickness of $4 \%$ of chord length provided the best performance. This thickness is much thinner than a rotor blade, but is close to the tip thickness of a conventional ducted fan or propeller blade.

The number of blades also plays a role in the hovering efficiency. As shown in Figure 7c, 32 blades generated the optimal result. More than 32 blades reduced the figure of merit, probably because too many blades increase the wet area and friction drag. Too few blades not only reduced the efficiency, but also increased the unsteadiness of the induced flow. This conclusion is only valid for very large ducted fans. For smaller ducted fans, such as the diameter around or less than $2 \mathrm{~m}, 3$ or 4 blades work better.

The shape of inlet lip plays an important role in improving hovering efficiency. Table 2 shows, when the radius of curvature of inlet lip $R_{\text {lip }}$ increased from $2.5 \%$ to $4.7 \%$, the figure of merit increased from 0.665 to 0.704 . This result is consistent to other's observation that larger inlet lip radius promotes hover performance $[7,24]$. However, $R_{\text {lip }}$ is constrained by the depth of duct because the duct cannot be very thick in order to reduce the aerodynamic drag in cruise flight. The $R_{\text {lip }}$ is also constrained by the width of outer wing, but this is not a problem for a fin-in-wing configuration because the outer wing is usually wide enough. However, this is a problem for a shrouded fan because the thickness of shroud is also limited.

Table 2. The effect of the radius of inlet lip on the figure of merit.

\begin{tabular}{cccc}
\hline $\boldsymbol{R}_{\text {lip }}$ & $2.5 \%$ & $3.6 \%$ & $4.7 \%$ \\
\hline Figure of Merit & 0.665 & 0.683 & 0.704 \\
\hline
\end{tabular}


Figure $7 \mathrm{~d}$ shows the effect of blade aspect ratio or chord length on the performance of the annular lift fan. Reducing the blade chord length almost half to the aspect ratio of 3.5 4.0 further increased the figure of merit to 0.733 . This figure is as high as 0.73 of the two-stage fans in the previous study [10]. The two-stage fans use counter rotating upper fan and lower fan to eliminate swirl loss and increase hover efficiency. For the single-stage fans, without the elimination of swirl loss, high efficiency was still achieved due to the improved inlet lips. Because the two-stage fans occupied much of the duct volume, the radii of inlet lips could only be small. For the single-stage fans, more duct space was saved for larger inlet lips, so the improvement in efficiency offset the swirl loss to achieve the same figure of merit as the two-stage fans. If the swirl loss of the single-stage fans could be further reduced by a stator, the figure of merit would be higher. However, the efforts to reduce the swirl loss always lead to strong interactions between the rotor and stator and result in oscillation and vibration of the aircraft in transition, so the number of stator blades cannot be many and the improvement of FM is very limited.

With the aspect ratio of 4.0 (chord length $0.5 \mathrm{~m}$ ), taper or twist of blades did not further increase the figure of merit. Twist of blades deteriorated the performance. The role of taper and twist for an annular fan was not as important as for a circular lift fan probably because the annular fan is only equivalent to the peripheral $28 \%$ part of a circular fan. Even for a conventional circular fan, taper and twist of this part are relatively small.

With the higher aspect ratio, further changing blade pitch angle, the number of blades, or blade thickness did not further increase FM. Increasing the length of diffuser definitely would improve FM, but the increase is seriously restricted by the depth of duct. The increase of length of diffuser must lead to the decrease of $R_{\text {lip }}$, so the improvement is very limited.

Therefore, the maximum figure of merit that could be achieved by the annular lift fan was 0.733 $\left(\sigma=1.03, P_{\text {actual }}=2293 \mathrm{kw}, 137 \mathrm{rpm}\right)$, with power loading $4.50 \mathrm{~kg} / \mathrm{kw}$ at disc loading $138.5 \mathrm{~kg} / \mathrm{m}^{2}$.

Compared to the numerical simulation results of a 10-m 32-bladed conventional circular lift fan with the same airfoil ( $4 \%$ thickness, chord length $0.5 \mathrm{~m})$, the same fan area $\left(75.3 \mathrm{~m}^{2}\right)$, the same disc loading $\left(138.5 \mathrm{~kg} / \mathrm{m}^{2}\right)$, the same duct depth $(1 \mathrm{~m})$, the same duct inlet lip shape and outer wing width $(2.5 \mathrm{~m})$ (Figure 8), the highest figure of merit achieved was $0.751\left(\sigma=1.07, P_{\text {actual }}=2187 \mathrm{kw}, 203 \mathrm{rpm}\right)$. The circular lift fan seems more efficient than the annular lift fan. This is probably because of the low pressure underneath the central fuselage of the annular fan as shown in Figure 9a. The low pressure caused the fuselage to generate a net negative lift. The hub of circular fan is much smaller than the fuselage, so it generated much smaller negative lift (Figure 9b), thus this makes the circular fan more efficient. However, when the aircraft is close to the ground, the ground effect will play an important role. As shown in Figure 10a, under the strong ground effect, the pressure underneath the fuselage of the annular lift fan aircraft became positive, producing a net positive lift, while the ground effect on the circular fan was very weak (Figure 10b). When the distance between the aircraft and the ground was $10 \mathrm{~m}$, the annular lift fan aircraft could achieve the figure of merit of $0.832\left(\sigma=1.10, P_{\text {actual }}=1928 \mathrm{kw}\right.$, $119 \mathrm{rpm})$, much higher than $0.749\left(\sigma=0.87, P_{\text {actual }}=2420 \mathrm{kw}, 200 \mathrm{rpm}\right)$ of the circular lift fan. The high pressure was generated beneath the central fuselage because the exit flow from the annular duct enclosed the space between the ground and the bottom of fuselage, while the hub of circular fan was too small to produce significant lift and the interactions between the high pressure and the fan blades somehow reduced the lift of the duct and the figure of merit. The power loading of $5.2 \mathrm{~kg} / \mathrm{kw}$ for the annular lift fan under the ground effect is much higher than $4.2 \mathrm{~kg} / \mathrm{kw}$ for the circular lift fan.

Even if a large circular lift fan may be more efficient than the annular lift fan in hover, it is difficult to lay out the fuselage for such an aircraft with such a large fan. For an aircraft with a plurality of smaller circular fans around a central fuselage, other problems such as increased complexity may arise.

In practice, for most modern helicopter rotors, FM values of 0.7 and 0.8 represent a good hovering performance [25], thus the FM of 0.733 of the annular lift fan is good enough for general aviation. In addition, the annular lift fan only works during VTOL when it is close to the ground, so the actual FM can be as high as 0.832 .

The parameters of optimal annular lift fan can be summarized in Table 3. 


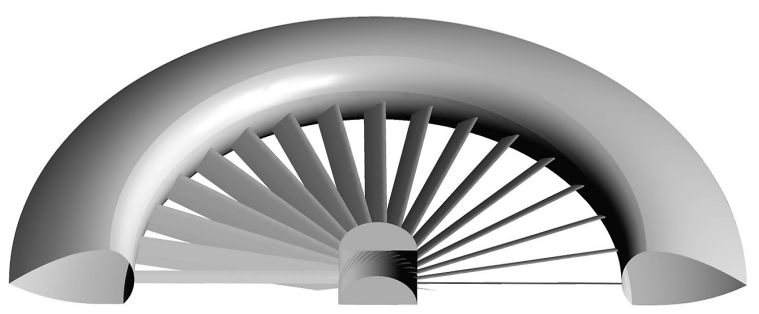

Figure 8. Large circular lift fan.

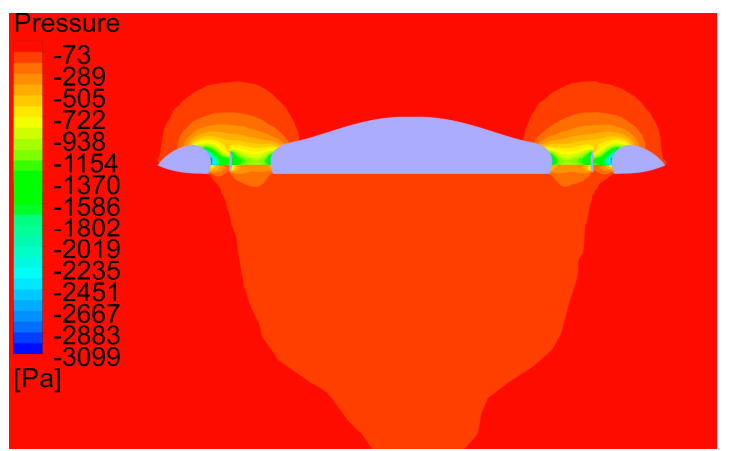

(a)

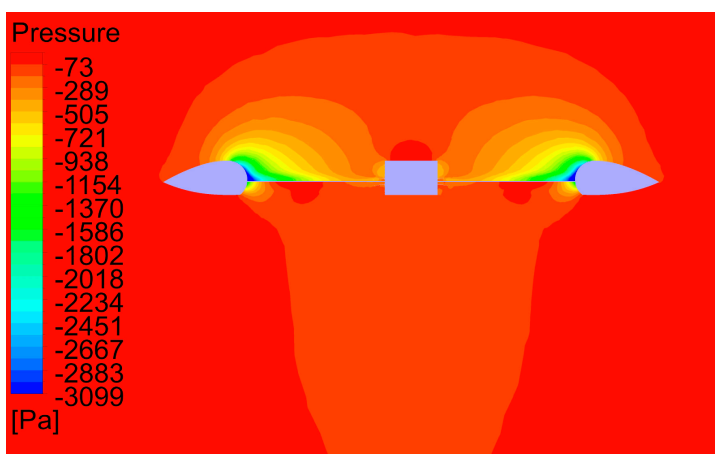

(b)

Figure 9. Pressure contour in the central plane of ducted fans. (a) Annular lift fan aircraft with two parallel counter rotating fans [15]; (b) Circular lift fan.

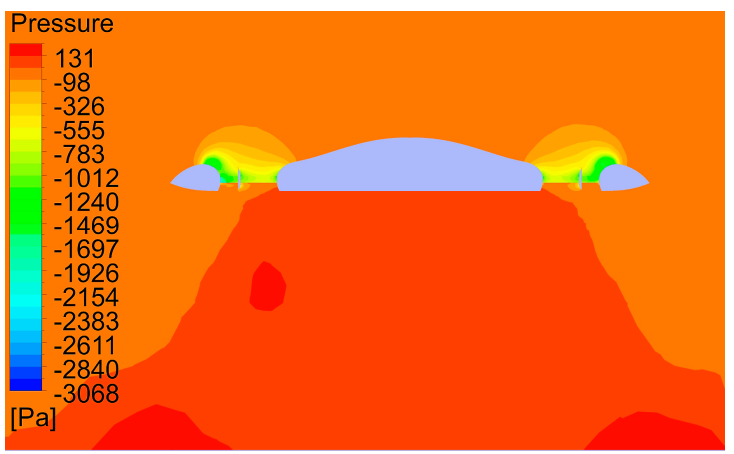

(a)

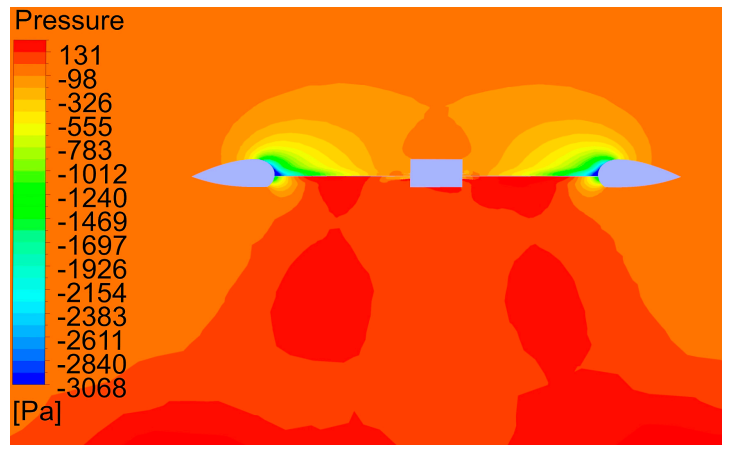

(b)

Figure 10. Pressure contour in the central plane of ducted fans under the ground effect. (a) Annular lift fan aircraft with two parallel counter rotating fans [15]; (b) Circular lift fan.

Table 3. The optimized parameters of annular lift fan system.

\begin{tabular}{ccccc}
\hline Pitch Angle & Thickness & Number of Blades & $\boldsymbol{R}_{\text {lip }}$ & Blade Aspect Ratio \\
\hline $27^{\circ}$ & $4 \%$ & 32 & $4.7 \%$ & $3.5 \sim 4.0$ \\
\hline
\end{tabular}

The improvement of airfoil with smooth leading edge may possibly further increase the maximum FM, but as the FM has been already high, the improvement will be limited and is not within the scope of this present investigation.

The optimized narrow and thin blades not only save space in the duct for larger $R_{\text {lip }}$ of inlet lip, longer diffuser, for stator and struts, but also reduce the dead weight of fan. As the fan is tip driven by engines incorporated in the outer wing, the blade tips are fixed in the duct wall. The fan becomes strong and can be made of non-metal material to reduce the dead weight. 
The optimized annular lift fan aircraft also has lower momentum drag and nose up pitching moment in transition [15], due to the reduced chord length and width of outer wing.

\section{Conclusions}

Numerical simulations were conducted on an annular lift fan aircraft to investigate the effects of different parameters on the performance of hovering. The roles of pitch angle, thickness, chord length, number of blades, and shape of inlet lip were explored. The simulations were carried out with disc loading of $138.5 \mathrm{~kg} / \mathrm{m}^{2}$ and duct depth of $1 \mathrm{~m}$ based on $k-\omega$ SST turbulence model.

The simulation results showed the pitch angle of $27^{\circ}$, thin blade with the maximum thickness of $4 \%$ chord length, high aspect ratio of 3.5 4.0 produced the highest FM. The number of blades was also important. Too few blades for a large fan led to deteriorated and unstable performance, but too many blades also reduced efficiency. About 32 blades was the best choice. Twist of blades deteriorated the performance. Taper of blades did not improve the efficiency.

The radius of duct inlet lip played a key role in hovering efficiency. $R_{\text {lip }}$ should be as large as possible to ensure high figure of merit, but it was constrained by the depth of duct and width of outer wing. For a conventional ducted fan, $R_{\text {lip }}$ is primarily constrained by the thickness of shroud. For the fan-in-wing configuration, $R_{\text {lip }}$ is primarily constrained by the depth of duct. For the same reason, the length of diffuser exit is constrained for fan-in-wing, while it is usually not so constrained in the case of shrouded fans because the shroud is usually long enough. The maximum figure of merit achieved by the annular lift fan was 0.733 in hover, with power loading of $4.50 \mathrm{~kg} / \mathrm{kw}$.

The annular lift fan was less efficient than the circular lift fan of the same disc area in hover due to the low pressure beneath the central fuselage, but the annular lift fan was more efficient when close to the ground due to the ground effect and the high pressure beneath the fuselage. When the distance from the aircraft to the ground was $10 \mathrm{~m}$, the maximum FM achieved by the annular lift fan was 0.832 , with power loading of $5.2 \mathrm{~kg} / \mathrm{kw}$.

Acknowledgments: The authors would like to thank Hong-Wei Wang for the support of the software.

Author Contributions: Yun Jiang proposed the ideas, performed the CFD simulation and wrote the manuscript. Bo Zhang analyzed the data and provided software support.

Conflicts of Interest: The authors declare no conflict of interest.

\section{Nomenclature}

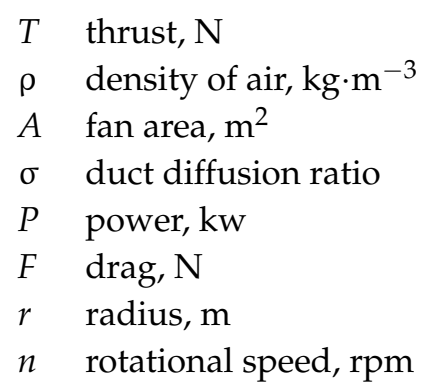

\section{References}

1. Thouault, N.; Breitsamter, C.; Adams, N.A. Numerical and experimental analysis of a generic Fan-in-wing configuration. J. Aircr. 2009, 46, 656-666. [CrossRef]

2. Diedrich, J.H. Summary of Model VTOL Lift Fan Tests Conducted at NASA Lewis Research Center; NASA TM X-71778; NASA Lewis Research Center: Cleveland, OH, USA, 1975.

3. Hickey, D.H.; Kirk, J.V. Survey of Lift-Fan Aerodynamic Technology; NASA CR-177615; NASA Ames Research Center: Moffett Field, CA, USA, 1993.

4. Prezedpelski, Z.J. Lift Fan Technology Studies; NASA CR-761; National Aeronautics and Space Administration: Washington, DC, USA, 1967. 
5. Taylor, J.W.R. Jane's All the World's Aircraft 1962-63; Sampson, Low, Marston \& Co Ltd.: London, UK, 1962.

6. Bevilaqua, P.M. Genesis of the F-35 joint strike fighter. J. Aircr. 2009, 46, 1825-1836. [CrossRef]

7. Pereira, J.I. Hover and Wind-Tunnel Testing of Shrouded Rotor for Improved Micro Air Vehicle Design. Ph.D. Thesis, University of Maryland, College Park, MD, USA, 2008.

8. Asmus, F.J. Design and development of the tip turbine lift fan. Ann. N. Y. Acad. Sci. 1963, 107, 147-176. [CrossRef]

9. Dyer, K.G. Aerodynamic Study of a Small, Ducted VTOL Aerial Vehicle. Master's Thesis, Massachusetts Institute of Technology, Cambridge, MA, USA, 2002; pp. 31-49.

10. Jiang, Y.; Zhang, B.; Huang, T. CFD study of an annular lift fan lift system for VTOL aircraft. Aerospace 2015, 2, 555-580. [CrossRef]

11. Piolenc, F.M.; de Wright, G.E., Jr. Ducted Fan Design: Volume 1-Propulsion Physics and Design of Fans and Long-Chord Ducts; Create Space Independent Publishing Platform: Middletown, DE, USA, 2015.

12. Simioni, N.; Ponza, R.; Benini, E. Numerical assessment of pneumatic devices on the wing/fuselage junction of a tiltrotor. J. Aircr. 2013, 50, 752-763. [CrossRef]

13. Akturk, A.; Camci, C. Tip clearance investigation of a ducted fan used in VTOL Unmaned Aerial Vehicles-Part I: Baseline experiments and computational validation. J. Turbomach. 2014, 136, 021004. [CrossRef]

14. Akturk, A.; Camci, C. Tip clearance investigation of a ducted fan used in VTOL Unmaned Aerial Vehicles-Part II: Novel treatments via computational design and their experimental verification. J. Turbomach. 2014, 136, 021005. [CrossRef]

15. Jiang, Y.; Zhang, B. Numerical study of transition of an annular lift fan aircraft. Aerospace 2016, 3, 30. [CrossRef]

16. Xu, H.Y.; Ye, Z.Y.; Shi, A.M. Numerical study of propeller slipstream based on unstructured overset grids. J. Aircr. 2012, 49, 384-389. [CrossRef]

17. Blocken, B.; Defraeye, T.; Koninckx, E.; Carmekiet, J.; Hespel, P. CFD simulations of the aerodynamic drag of two drafting cyclists. Comput. Fluids 2013, 71, 435-445. [CrossRef]

18. Malipeddi, A.K.; Mahmoudnejad, N.; Hoffmann, K.A. Numerical analysis of effects of leading-edge protuberances on aircraft wing performance. J. Aircr. 2012, 49, 1336-1344. [CrossRef]

19. Qu, Q.; Lu, Z.; Liu, P.; Agarwal, R.K. Numerical study of aerodynamics of a Wing-in-Ground-Effect craft. J. Aircr. 2014, 51, 913-924.

20. Al-Garni, A.Z.; Saeed, F.; Al-Garni, A.M. Experimental and numerical investigation of 65 degree Delta and 65/40 degree double-delta wings. J. Aircr. 2008, 45, 71-75. [CrossRef]

21. Liu, Z.; Albertani, R.; Moschetta, J.M.; Thipyopas, C.; Xu, M. Experimental and computational evaluation of small microcoaxial rotor in hover. J. Aircr. 2011, 48, 220-228. [CrossRef]

22. Menter, F.R. Zonal two equation $k$ - $\omega$ turbulence models for aerodynamic flows. In Proceedings of the $23 \mathrm{rd}$ Fluid Dynamics, Plasmadynamics, and Lasers Conference, Orlando, FL, USA, 6-9 July 1993.

23. Menter, F.R. Two-equation eddy viscosity turbulence models for engineering applications. AIAA J. 1994, 32, 1598-1605. [CrossRef]

24. Sheng, C.; Zhao, Q.; Bi, N.P. Numerical investigations of ducted fan hover performance for Fan-In-Wing applications. In Proceedings of the AIAA 2015 SciTech Conferences, Kissimmee, FL, USA, 5-9 January 2015.

25. Leishman, J.G. Principles of Helicopter Aerodynamics; Cambridge University Press: Cambridge, UK, 2000.

(C) 2016 by the authors; licensee MDPI, Basel, Switzerland. This article is an open access article distributed under the terms and conditions of the Creative Commons Attribution (CC-BY) license (http://creativecommons.org/licenses/by/4.0/). 